\section{Correspondence}

https://doi.org/10.11646/zootaxa.5040.3.9

http://zoobank.org/urn:lsid:zoobank.org:pub:10E304B7-A7FC-4292-8063-5D8A9CF86460

\title{
First record of an extant species of the family Stenurothripidae from China (Insecta:Thysanoptera)
}

\author{
QINGJING FENG ${ }^{1,2} \&$ XIAOLI TONG ${ }^{1 *}$ \\ ${ }^{1}$ Department of Entomology, College of Plant Protection, South China Agricultural University, Guangzhou 510642, China. \\ 2 ”-fengqingjing97@163.com; @ https://orcid.org/0000-0001-9248-9082 \\ *Corresponding author. !"xtong@scau.edu.cn; @ https://orcid.org/0000-0003-1731-229X
}

The family Stenurothripidae, originally erected by Bagnall (1927) based on the fossil genus Stenurothrips Bagnall (Mound et al. 1980), is one of nine families recognised in the Thysanoptera. Currently, 25 species of 13 genera are known in this family from the world (ThripsWiki 2021), but only six are extant species, and these are placed in three genera. Two of these genera, Oligothrips Moulton and Heratythrips Mound \& Marullo, each include a single living species and these are known only from North America (Mound \& Marullo 1998; Wiesenborn 2021). The other genus, Holarthrothrips Bagnall, comprises four species and these are recorded only between the Mediterranean region and India (Bhatti 1986). In those areas, these four species are considered to be associated with the inflorescences of Phoenix spp. (Bhatti \& Ananthakrishnan 1978; Bhatti 1986; Mound LA, personal communication 2021). Recently, Holarthrothrips indicus Bhatti \& Ananthakrishnan has been newly discovered in southern China. This new distribution record of the family takes the number of Thysanoptera families found in China to six.

\section{Holarthrothrips indicus Bhatti \& Ananthakrishnan (Figs 1-10)}

Holarthrothrips indicus Bhatti \& Ananthakrishnan, 1978: 229.

Female macroptera. Body dark brown (Fig. 1). Antennal segments I and II pale brown, III and IV yellow, V-IX dark brown; fore wing pale, without any shadings (Fig. 7); legs yellow except femora slightly shaded along outer margin. Head (Fig. 3) slightly wider than long, sculptured with transverse anastomosing striae dorsally; three pairs of ocellar setae subequal in length, pair III arising within ocellar triangle; postocular setae apparently biserial, six pairs of short setae in oblique row and two pairs of longer setae near middle of dorsum. Antennae 9-segmented (Fig. 5), all segments well separated, III \& IV each with a conical sense cone with wider base (Fig. 6); segment I without paired dorso-apical setae, II-IX with transverse rows of microtrichia, IX approximately five times longer than wide. Maxillary palps 3-segmented. Cephalic tentorium full developed, tentorial bridge complete, connected with anterior tentorial arms and posterior tentorial arms, the anterior arms slender, but the bases clearly visible. Pronotum wider than long, with transverse anastomosing striae; two pairs of anteromarginal setae distinctly longer than discal setae; one pair of long posteroangular setae and 7 pairs of posteromarginal setae present. Mesonotum (Fig. 4) with transverse lines of sculpture between and around campaniform sensilla (CPS) near anterior margin, median pair of setae arising well in front of posterior margin. Metascutum with concentric rings of sculpture bearing microtrichia (Fig. 4), one pair of setae close to posterior margin and one pair of longer setae near anterior margin; CPS present posteromedially. Fore wing (Fig. 7) first vein with 17-20 setae, arranged in a nearly continuous series or with short irregular intervals; second vein with continuous series of 15-18 setae; clavus with 8 veinal setae and one discal seta near base; posteromarginal fringe cilia straight. Prosternal ferna weakly connected at middle; basantra membranous, without setae; prospinasternum transverse. Mesosternum with sternopleural sutures complete (Fig. 2) and with endofurcal spinula. Metasternal sternopleural sutures absent (Fig. 2), endofurca without spinula. Tarsi 2-segmented, fore tarsus with a small recurved claw. Abdominal tergites with transverse lines of sculpture; tergite I with posterior pair of CPS (Fig. 8), II-IX with median pair of CPS, X with anterior pair of CPS; tergites II-VII with paired longitudinal weakly chitinized fissures sublaterally (Fig. 10); II-VIII lateral thirds with numerous ciliate microtrichia on sculpture lines; VII-VIII with complete comb of long microtrichia on posterior margin (Fig. 10), but no comb medially on remaining tergites; X without median split. Sternites II-III each with 2 discal setae, IV-VII with 4-8 discal setae; sternites II-VI with complete posteromarginal comb of fine microtrichia, VII absent the comb medially; posterior margins on sternites III-VII with 4 pairs of setae, II with 2 pairs, S1 setae on VII at posterior margin (Fig. 9). 
Material examined. China, Guangdong Province, Guangzhou City, the campus of South China Agricultural University. 4 females collected from Cordyline fruticosa [Liliaceae], 7 females from Osmanthus fragrans [Oleaceae], one female from Ligustrum quihoui [Oleaceae], 27.xii.2020 (Qingjing Feng).

Remarks. In colour and structure H. indicus is very similar to H. josephi known from Iraq and Iran (Minaei 2013). However, josephi lacks CPS on abdominal tergite I, and tergites II-VI have the posteromarginal comb of fine microtrichia complete medially (Bhatti 1986). H. indicus is also similar to H. tenuicornis in general appearance, but it can be distinguished easily by the unshaded fore wings, by the absence of oblique sternopleural sutures on the metasternum, and the presence of discal setae on the abdominal sternites. Although, as indicated above, the species of Holarthrothrips are considered to live in the inflorescences of Phoenix spp., we collected H. indicus only from three plants in unrelated families. These collections were made in the winter, and it is possible that this thrips may disperse to various evergreen plants for overwintering in southern China.

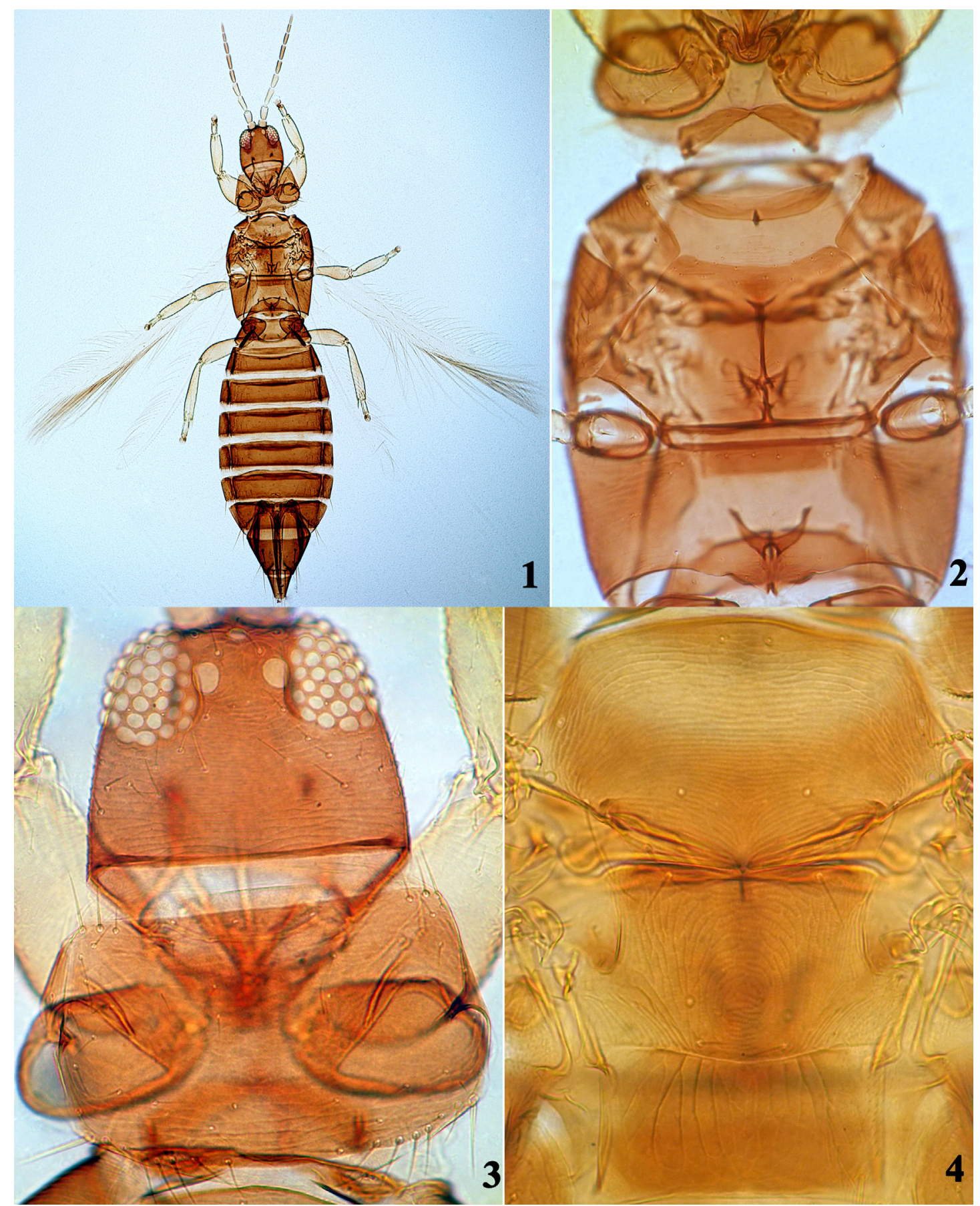

FIGUERS 1-4. Holarthrothrips indicus: (1) Female; (2) Prosternum, meso- \& metasternum; (3) Head \& pronotum; (4) Meso\& metanotum 


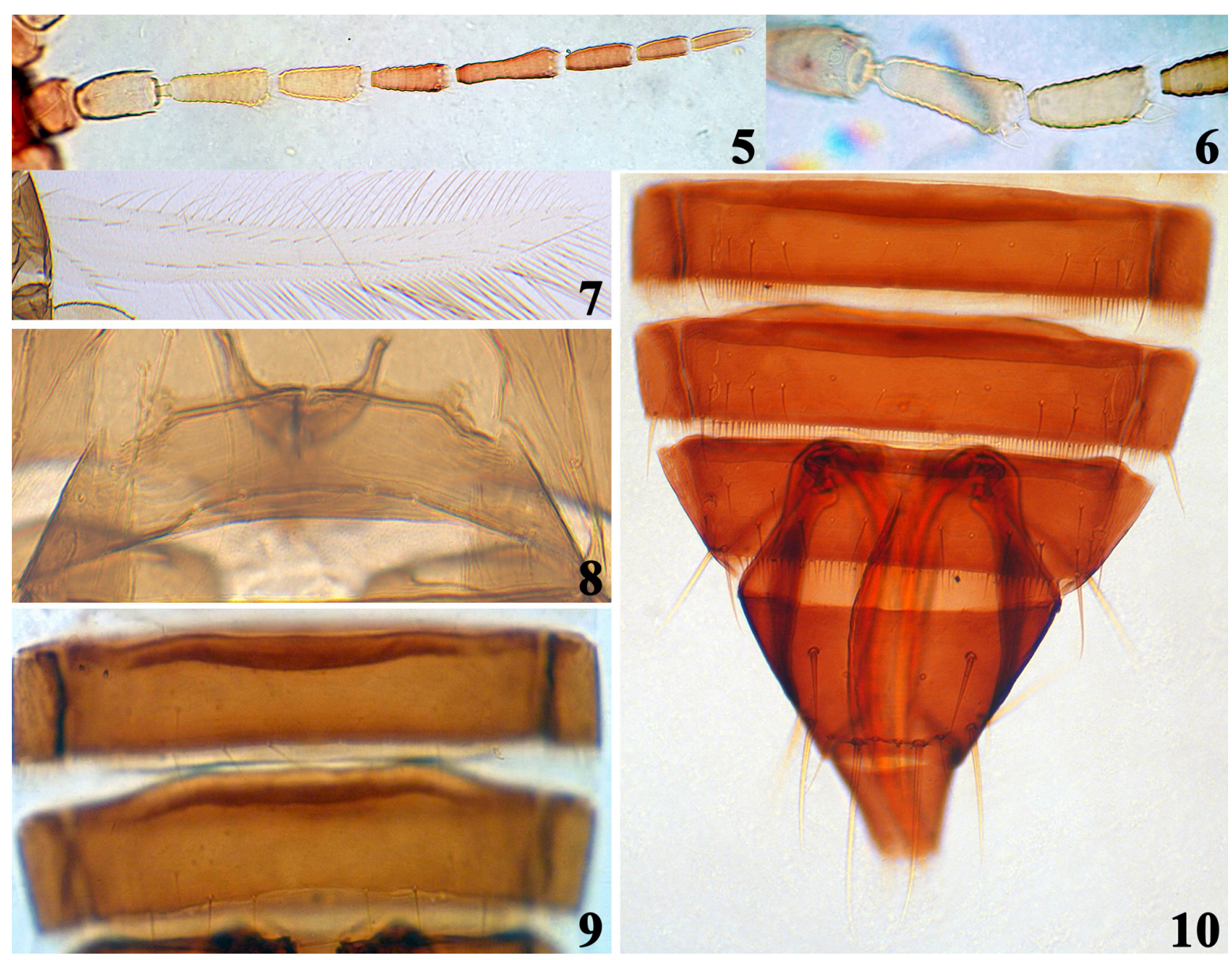

FIGURES 5-10. Holarthrothrips indicus: (5) Antenna; (6) Antennal segments II- IV; (7) Fore wing; (8) Abdominal tergite I; (9) Sternites VI \& VII; (10) Tergites VI-X.

\section{Acknowledgements}

We are grateful to Laurence Mound (CSIRO) for kindly checking the specimens of H. indicus in ANIC. Thanks are also due to Prof. Xinsheng Qin (South China Agricultural University) for identifying host plants.

\section{References}

Bagnall, R.S. (1927) Contributions towards a knowledge of the European Thysanoptera. III. Annals and Magazine of Natural History, Series 9, 20, 561-585. https://doi.org/10.1080/00222932708655491

Bhatti, J.S. (1986) A new species of Holarthrothrips from Iraq, with notes on host plants and key to species, along with clarification of the position of this genus among Thysanoptera. Zoology (Journal of Pure and Applied Zoology), 1, 1-33. https://doi.org/10.46318/Zoology.1.1.1986.1-33

Bhatti, J.S. \& Ananthakrishnan, T.N. (1978) Studies in Some Indian Thysanoptera. Entomon, 3, 229-238.

Minaei, K. (2013) Thrips (Insecta, Thysanoptera) of Iran: a revised and updated checklist. ZooKeys, 330, 53-74. https://doi.org/10.3897/zookeys.330.5939

Mound, L.A., Heming, B.S. \& Palmer, J.M. (1980) Phylogenetic relationships between the families of recent Thysanoptera. Zoological Journal of the Linnean Society of London, 69, 111-141. https://doi.org/10.1111/j.1096-3642.1980.tb01934.x

Mound, L.A. \& Marullo, R. (1998) Two new basal-clade Thysanoptera from California with Old World affinities. Journal of the New York Entomological Society, 106 (2-3), 81-94.

ThripsWiki (2021) ThripsWiki-providing information on the World's thrips. Available from: http://thrips.info/wiki/Main_Page (accessed 20 August 2021)

Wiesenborn, W.D. (2021) New distribution records of Heratythrips sauli Mound \& Marullo, 1998 (Thysanoptera: Stenurothripidae), with description of the first known adult male. The Pan-Pacific Entomologist, 97 (1), 7-11. https://doi.org/10.3956/2021-97.1.7 